Intervention: introduction of bDMARDs and associated publication of bDMARD recommendations in Denmark in 2002.

Statistical analyses: 5-year age- and sex-standardised incidence rates of THR and TKR calculated for incident RA patients diagnosed biannually in 1996-2011, and GPCs. Secular trends in the pre-bDMARD guideline era (1996-2002) were compared with those in the bDMARD period (2003-2016) using segmented linear regression and a 1-year lag period (2002-03). Absolute changes in TKR and THR at the midpoint (February 2007) between guideline implementation and end of study period were estimated.

Results: In total, during 1996 to 2011, 30868 incident RA patients were identified (mean age at diagnosis 58.3 years, 70\% women) and compared with 301527 GPCs. See Table for results.

Table 1. Changes in 5-year incidence rate of total hip (THR) or total knee replacement (TKR) in incident rheumatoid arthritis (RA) patients following introduction of biological DMARDs compared with secular trends in age, sex and municipality-matched general population controls (GPC)

\begin{tabular}{ccccccc}
\hline Cohort & & $\begin{array}{c}n \\
\text { THR/TKR }\end{array}$ & $\begin{array}{c}\text { Baseline incidence } \\
\text { rate/1000 person years }\end{array}$ & $\begin{array}{c}\Delta \text { per year } \\
\text { pre-2002 }\end{array}$ & $\begin{array}{c}\Delta \text { in } \\
\text { level 2003 }\end{array}$ & $\begin{array}{c}\Delta \text { per year } \\
\text { post-2003 }\end{array}$ \\
\hline TKR & RA & 865 & 5.87 & +0.19 & - & -0.20 \\
& GPC & 2438 & 0.42 & +0.21 & - & +0.08 \\
THR & RA & 935 & 8.72 & -0.38 & +2.23 & -0.38 \\
& GPC & 4744 & 2.89 & +0.11 & - & +0.02 \\
\hline
\end{tabular}

Stepwise backward elimination to produce most parsimonious model: $p$-entry $<0.05$ and $p$-exit 0.2. ${ }^{*} \Delta$ per year based on biannual data.

Incidence rate of TKR in newly diagnosed RA patients and matched GPCs

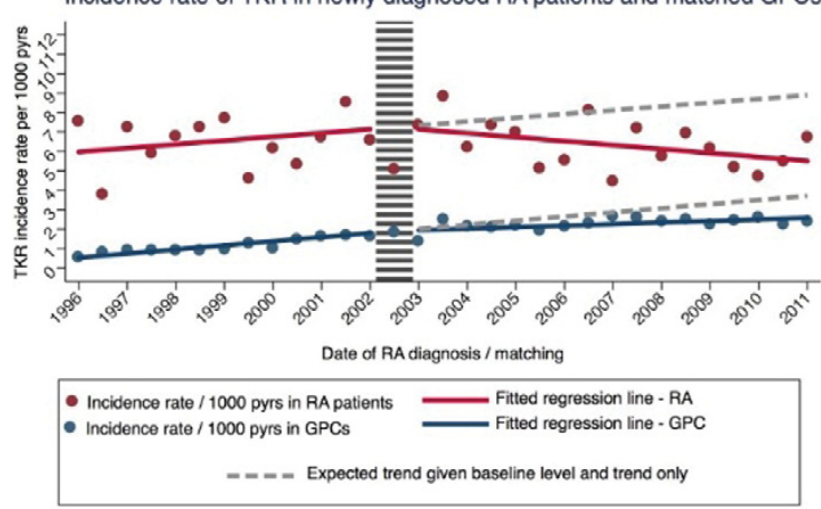

Conclusions: Prior to 2002, the incidence of TKR increased among RA patients, but started to decrease after introduction of bDMARDs and their associated guidelines in 2003 (absolute change -1.8 TKRs/1000 person years in Feb. 2007). In contrast, the incidence of TKR increased among GPCs throughout the entire study period. The incidence of THR increased in GPCs for the entire duration of the study period, whereas there was a downward going trend among RA patients, but with a surprising level increase in 2003. The overall patterns of our findings are in line with those recently reported from England and Wales ${ }^{1}$.

References:

[1] Hawley S, Cordtz R, Dreyer L, et al. The Impact of Biologic Therapy Introduction on Hip and Knee Replacement Among Rheumatoid Arthritis Patients: An Interrupted Time Series Analysis Using the Clinical Practice Research Datalink. Arthritis Rheumatol 2016;68.

Disclosure of Interest: R. Cordtz: None declared, S. Hawley: None declared, D. Prieto-Alhambra Grant/research support from: DPA's group has received unrelated research grants from Amgen and Servier, L. E. Kristensen Speakers bureau: Pfizer, AbbVie, Amgen, UCB, Celgene, BMS, MSD, Novartis, Eli Lilly, Janssen Pharmaceuticals, S. Overgaard: None declared, A. Odgaard: None declared, L. Dreyer: None declared

DOI: 10.1136/annrheumdis-2017-eular.1227

\section{OP0252 RHEUMATOID ARTHRITIS PATIENTS WITH CONTINUED LOW DISEASE ACTIVITY HAVE SIMILAR OUTCOMES OVER 10 YEARS, REGARDLESS OF INITIAL THERAPY}

S.A. Bergstra ${ }^{1}$, R.B. Landewé ${ }^{2,3}$, T.W. Huizinga ${ }^{1}$, C.F. Allaart ${ }^{1} .{ }^{1}$ Rheumatology, LUMC, Leiden; ${ }^{2}$ Amsterdam Rheumatology \& Immunology Center, Amsterdam; ${ }^{3}$ Zuyderland Medical Center, Heerlen, Netherlands

Background: Low disease activity and remission in rheumatoid arthritis (RA) patients is achieved earlier and in higher frequency when the initial treatment includes a combination of methotrexate (MTX) with corticosteroids or a biologic disease modifying anti-rheumatic drug than MTX alone. However, it is unknown whether in patients with early and persistently good response the initial treatment still has an impact on long term outcomes.

Objectives: To compare 10 years disease outcomes of RA patients with persistent low disease activity on MTX monotherapy or on initial combination therapy with infliximab or prednisone and sulfasalazine.

Methods: RA patients with 10 years follow-up from the BeSt study were analyzed. RA patients fulfilling the American College of Rheumatology 1987 criteria with $<2$ years symptom duration were "treated to target" aiming at disease activity score (DAS) $\leq 2.4$, assessed with 3-monthly intervals. Patients in arms 1 and 2 started MTX monotherapy, patients in arm 3 started MTX, sulfasalazine and prednisone and patients in arm 4 started MTX and infliximab. All had DAS $\leq 2.4$ from $t=6$ months until $\mathrm{t}=10$ years and therefore stayed on initial treatment, with patients in arms 3 and 4 tapering to monotherapy within 10 months. Patients in arms 1 and 2 were compared with patients in arms 3 and 4 . Between-group differences over time were compared using (generalized) linear mixed model analyses, for the outcomes DAS, Health Assessment Questionnaire (HAQ), erythrocyte sedimentation rate (ESR), visual analogue scale (VAS) patient global health (range 0-100), percentage patients in remission and drug free remission and percentage patients with Sharp/van der Heijde score progression $\geq 5$.

Results: At $t=10$ years $28 / 247(11 \%)$ patients in arms 1 and 2 had sustained DAS $\leq 2.4$ compared to $68 / 261$ (26\%) patients in arms 3 and 4 . Patients in arms 1 and 2 were less often ACPA positive ( $46 \%$ versus $54 \%, p=0.477$ ), had shorter symptom duration at baseline [median (range) 14 (1-191) versus 18 (4-263) weeks, $p=0.004]$ and less radiologic damage progression after 10 years $[0(0-16)$ versus $2.5(0-26), p=0.014]$ than patients in arms 3 and 4 . No between-group differences were found over time, except for the percentage of patients in drug free remission. Significant group-time interactions were found for DAS, ESR and VAS patient's global health, but not $\mathrm{HAQ}$, percentage remission and percentage drug free remission, with slightly worse results over time for arms 3 and 4 compared to arms 1 and 2 (table 1).

\begin{tabular}{|c|c|c|c|}
\hline & Linear Mixed Model Analyses & $\beta$ & $95 \% \mathrm{Cl}$ \\
\hline \multirow[t]{2}{*}{ HAQ } & Treatment group ${ }^{*}$ & 0.076 & $-0.066 ; 0.22$ \\
\hline & Time & -0.0034 & $-0.0044 ;-0.0025$ \\
\hline \multirow[t]{3}{*}{ DAS } & Treatment group & 0.031 & $-0.24 ; 0.18$ \\
\hline & Time & .0 .029 & $-0.037 ;-0.021$ \\
\hline & Treatment group"Time & 0.0056 & $0.0012 ; 0.010$ \\
\hline \multirow[t]{3}{*}{ ESR } & Treatment group" & -3.30 & $-7.54 ; 0.93$ \\
\hline & Time & -0.19 & $-0.31 ;-0.072$ \\
\hline & Treatment group"Time & 0.11 & $0.041 ; 0.17$ \\
\hline VAS patient global & Treatment group' & -4.07 & $-9.50,1.37$ \\
\hline \multirow[t]{3}{*}{ health } & Time & -0.42 & $-0.57 ;-0.27$ \\
\hline & Treatment group*Time & 0.090 & $0.0048 ; 0.17$ \\
\hline & Genera lized linear mixed model analyses & OR & $95 \% \mathrm{Cl}$ \\
\hline \multirow{2}{*}{$\begin{array}{l}\text { SvdH score } \\
\text { progression }=5\end{array}$} & Treatment group & 0.83 & $0.17 ; 4.01$ \\
\hline & Time & 0.94 & $0.83 ; 1.07$ \\
\hline \multirow[t]{2}{*}{ Remission } & Treatment group ${ }^{\circ}$ & 0.58 & $0.32 ; 1.08$ \\
\hline & Time & 1.04 & $1.03 ; 1.04$ \\
\hline \multirow[t]{2}{*}{ Drug free remis sion } & Treatment group & 0.14 & $0.033 ; 0.61$ \\
\hline & Time & 1.06 & $1.03 ; 1.08$ \\
\hline
\end{tabular}

"Difference between treatment groups, MTX monotherapy responders as reference group, SE = standard error, $95 \% \mathrm{~d}=95 \%$ confidence interval

Conclusions: More patients achieved continuous low disease activity on prednisone or infliximab combination therapy tapered to MTX monotherapy than on MTX monotherapy, but there appear no additional benefits of combination treatment strategies for patients who have sustained DAS $\leq 2.4$. Regardless of initial induction therapy, those who remain in low disease activity have similar long term outcomes, with only the proportion of patients in drug free remission being higher in the MTX monotherapy group. These results strongly suggest that rapid achievement of remission/LDA itself, rather than how you achieve it, is crucial for determining long-term outcome in RA.

Disclosure of Interest: None declared

DOI: 10.1136/annrheumdis-2017-eular.1707

\section{OP0253 PASSIVE SMOKING IN CHILDHOOD AND HISTORY OF CHRONIC DIARRHEA INCREASES THE RISK OF DEVELOPING RHEUMATOID ARTHRITIS (RA)}

R. Seror ${ }^{1,2}$, G. Gusto ${ }^{3}$, M.C. Boutron-Ruault ${ }^{3}$, X. Mariette ${ }^{1,2} .{ }^{1}$ Rheumatology, Hopitaux Universitaires Paris Sud; ${ }^{2}$ INSERM U1184, Université Paris-sud, le Kremlin-Bicetre; ${ }^{3}$ Centre de recherche en epidemiologie et santé des populations, Inserm U1018, Villejuif, France

Objectives: To analyse the impact of active and passive smoking and intestinal transit disorders on the risk of incident RA

Methods: This study is based on the French E3N cohort ("Etude Epidémiologique auprès de femmes de l'Education Nationale"), which included 98,995 women volunteers born between 1925 and 1950 and prospectively followed since 1990 . Eleven self-administered questionnaires were sent to the participants between 1990 and 2014 to collect medical, demographic, environmental and hormonal data and dietary habits. The diagnosis of RA was collected on 2 successive questionnaires. Cases were considered certain if having declared RA and had taken a RA specific medication (methotrexate, leflunomide or biologic) since 2004 (period from which drug reimbursement data was available). Only incident and certain cases were included. Women were excluded if they had an inflammatory bowel disease and/or no information on their smoking status. Passive smoking was assessed by the following question: "When you were children, did you stay in a smoky room?". Patients were considered exposed if the answer was "yes, a few hours, or yes, several hours a day". The usual intestinal transit, reported by women prior to RA diagnosis (on average 10 years), were classified as normal 
transit, chronic diarrhoea, chronic constipation, and alternation between diarrhoea and constipation.

The risk of incident RA was estimated using an age-adjusted Cox model that considers smoking status as a time-dependent variable.

Results: 70598 women from the E3N study were included in the study. A total of 1239 patients reported an incidental RA, of which 350 cases were included in the study (and 280 in the analysis of intestinal transit disorders). Non-ascertained cases were excluded form the analyses. The age at inclusion in the study was 49.0 years $( \pm 6.4)$. The mean duration of follow-up was $21.2( \pm 1.3)$ years.

Passive smoking exposure during childhood increased the association between the RA risk active and adult active smoking. In ever smokers who had childhood passive exposure to smoke, the HR was $1.73[1.20 ; 2.50]$ as compared with non-smokers who were not exposed during childhood, while it was 1.37 [1.08; 1.73] in active smokers who were not exposed during childhood.

A history of chronic diarrhea was associated with increased RA risk (HR $=2.32$ $[1.41,3.81])$, while chronic constipation or alternation between diarrhoea and constipation did not.

\begin{tabular}{|c|c|c|c|}
\hline Smoking status & $\begin{array}{c}\text { Controls (\%) } \\
N=70248\end{array}$ & $\begin{array}{l}R A(\%) \\
N=350\end{array}$ & $\mathrm{HR}[95 \% \mathrm{Cl}]$ \\
\hline $\begin{array}{l}\text { Non smoker } \\
\text { No passive smoking in childhood }\end{array}$ & $32440(46,18)$ & $137(39,14)$ & Reference \\
\hline $\begin{array}{l}\text { Non smoker } \\
+ \text { Passive smoking in childhood }\end{array}$ & $5010(7,13)$ & $30(8,57)$ & $1,43[0,97 ; 2,13]$ \\
\hline $\begin{array}{l}\text { Ever smoker } \\
\text { No passive smoking in childhood }\end{array}$ & $27394(39,00)$ & $147(42,00)$ & $1,37[1,08 ; 1,73]$ \\
\hline $\begin{array}{l}\text { Ever smoker } \\
+ \text { Passive smoking in childhood }\end{array}$ & $5404(7,69)$ & $36(10,29)$ & $1,73[1,20 ; 2,50]$ \\
\hline Normal transit & 44254 (71.48) & $187(66.79)$ & Reference \\
\hline Chronic diarrhea & $1707(2.76)$ & $17(6.07)$ & $2.32[1.41 ; 3.81]$ \\
\hline Constipation & $8661(13.99)$ & $43(15.36)$ & $1.16[0.84 ; 1.62]$ \\
\hline $\begin{array}{l}\text { Alternating diarrhea - } \\
\text { constipation }\end{array}$ & $7291(11.78)$ & 33 (11.79) & $1.07[0.74 ; 1.55]$ \\
\hline
\end{tabular}

Conclusions: This study confirms the link between active smoking and the risk of RA. It suggests for the first time that in smokers, exposure to tobacco early in life, through passive smoking in childhood significantly increases this risk. Our study highlights the importance of avoiding any tobacco environment in children, especially in those with a family history of RA. Also, it shows for the first time an association between a history of chronic diarrhoea and the risk of developing RA. The association supports the hypothesis of dysbiosis (microbiota abnormality) as a risk factor for the emergence of autoimmunity. These data perfectly fit with the preclinical scheme of RA where an external event occurs at an early stage to promote emergence of auto-immunity, followed years after by clinical RA.

Disclosure of Interest: None declared

DOI: 10.1136/annrheumdis-2017-eular.3853

\section{FRIDAY, 16 JUNE 2017}

\section{HPR move to improve}

\section{OP0254-HPR HAND EXERCISE FOR WOMEN WITH RHEUMATOID ARTHRITIS AND DECREASED ADL ABILITY: AN EXPLORATORY RANDOMISED CONTROLLED TRIAL}

K. Ellegaard, C. von Bülow, A. Røpke, C. Bartholdy, I.S. Hansen, S. Rifbjerg, R. Christensen, M. Henriksen, E. Waehrens. The Parker Institute, Frederiksberg, Denmark

Background: Decreased strength and range of motion in the hand are often seen in rheumatoid arthritis (RA). Positive effects on hand function in RA patients after hand exercise and individual education in joint projection including coping strategies (ADL education) is shown $(1 ; 2)$. However, it is unknown if a combination of both will further improve hand performance.

Objectives: To investigate the effect on ADL ability of a hand exercise program as add on to an ADL education program in women with RA.

Methods: Women with RA involving the hand on stable medication for at least three months were recruited.

At baseline participants were examined by a rheumatologist who assessed joints of the hand and ruled out contraindications for participation e.g. massive malalignment of the joints. Inflammatory markers of the blood, hand pain and grip strength were also measured. The ADL motor ability was assessed using the observation-based Assessment of Motor and Process Skills (AMPS). After baseline examination randomized to ADL education + hand exercises (intervention; IG) or only ADL education (control; $C G$ ) was made.

All participants received three to four sessions with an occupational therapist learning how to perform ADL tasks overcome their specific hand problems. The intervention group also received a hand exercise program, to be conducted four times a week, for eight weeks, containing exercises for improving range of motion and strength; once a week the exercise program was supervised by a physiotherapist, to correct and prevent overload and to increase load if possible. Primary outcome measure was change in observed ability to perform ADL tasks (AMPS) at week 8. Secondary outcomes include grip strength, pain, joint count, inflammatory markers and self-reported function.

After eight weeks, all baseline measures were repeated and changes from baseline were calculated based on the Intention To Treat (ITT) population.

Clinicaltrials.gov Identifier: (NCT02140866)

Results: Fifty five patients were randomised to IG ( $n=28)$ or CG ( $n=27) ; 22$ and 25 patients, respectively, completed the trial. The ITT-populations mean age was 63.8 (12.8) years, mean disease duration was 12.4 (11.0) years. Baseline tender and swollen joint count was $5.07(4.85)$ and $1.37(1.72)$ respectively, the hand pain was $41.95 \mathrm{~mm}$ (right) and $35.78 \mathrm{~mm}$ (left) (VAS) and hand grip strength was 18.25 $\mathrm{kg}$ (right) and $17.46 \mathrm{~kg}$ (left). Baseline AMPS ADL motor measure was $1.36(0.46)$. As judged by the $95 \%$ confidence intervals, no difference in change from baseline was seen between the groups (see table)

Change from baseline in and between groups (ITT analysis)

\begin{tabular}{|l|l|l|l|l|}
\hline & $\begin{array}{l}\text { Intervention group } \\
(\mathrm{n}=28)\end{array}$ & $\begin{array}{l}\text { Control group } \\
(\mathrm{n}=27)\end{array}$ & $\begin{array}{l}\text { Difference } \\
\text { between groups }\end{array}$ & $\mathrm{p}$-value \\
\hline AMPS motor & $0.24(0.09-0.39)$ & $0.20(0.05-0.35)$ & $0.04(-0.17-0.25)$ & 0.70 \\
\hline $\begin{array}{l}\text { Tender joint count } \\
(28 \text { joints })\end{array}$ & $-0.57(-1.86-0.73)$ & $0.35(-0.95-1.64)$ & $-0.92(-2.77-0.93)$ & 0.32 \\
\hline $\begin{array}{l}\text { Swollen joint } \\
\text { count }\end{array}$ & $0.25(-0.23-0.73)$ & $0.16(-0.32-0.64)$ & $0.10(-0.59-0.77)$ & 0.78 \\
\hline$(28$ joints $)$ & $-0.70(-2.41-1.02)$ & $1.77(-0.09-3.63)$ & $-2.45(-5.0-0.06)$ & 0.06 \\
\hline CRP & $-0.07(-0.17-0.03)$ & $0.01(-0.09-0.12)$ & $-0.08(-0.23-0.06)$ & 0.24 \\
\hline HAQ & $-1.17(-7.82-5.48)$ & $0.55(-6.23-7.31)$ & $-1.71(-11.20-7.79)$ & 0.72 \\
\hline $\begin{array}{l}\text { Hand pain activity } \\
\text { (VASmm) }\end{array}$ & $-3.43(-11.07-4.20)$ & $-0.81(-8.59-6.97)$ & $-2.62(-13.62-8.38)$ & 0.64 \\
Right/left & $1.43(0.40-2.45)$ & $0.18(-0.86-1.23)$ & $1.24(-0.23-2.71)$ & 0.10 \\
\hline $\begin{array}{l}\text { Hand strength } \\
\text { (kg) } \\
\text { Right/eft }\end{array}$ & $1.00(-0.47-2.47)$ & $-0.36(-1.83-1.11)$ & $1.36(-0.71-3.44)$ & 0.19 \\
\hline
\end{tabular}

Conclusions: $A$ hand exercise program as add on to an ADL education did not improve $A D L$ ability more than $A D L$ education alone in women with $R A$ experiencing decreased ADL ability involving the hands.

References:

[1] Masiero S et al. Effects of an educational-behavioral joint protection program on people with moderate to severe rheumatoid arthritis: a randomized controlled trial. Clin Rheumatol 2007 Dec;26:2043-50.

[2] Lamb SE et al. Exercises to improve function of the rheumatoid hand (SARAH): a randomised controlled trial. Lancet 2015 Jan 31;385(9966):421-9.

Disclosure of Interest: None declared

DOI: 10.1136/annrheumdis-2017-eular.2911

\section{OP0255-HPR AN ADD-ON PROGRAMME IMPROVED THE SHORT-TERM, BUT NOT THE LONG-TERM EFFECT OF REHABILITATION IN PATIENTS WITH RHEUMATIC DISEASES: RESULTS FROM A PRAGMATIC MULTI-CENTRE STEPPED-WEDGE CLUSTER RANDOMIZED CONTROLLED TRIAL}

G. Berdal $^{1}$, K. Hagen ${ }^{1}$, H. Dagfinrud ${ }^{1}$, P. Mowinckel ${ }^{1}$, I. Bø ${ }^{2}$, T.N. Dager ${ }^{1}$, A. Dingsør ${ }^{3}$, S. Eppeland ${ }^{4}$, J. Hagfors ${ }^{5}$, B. Hamnes ${ }^{2}$, M. Nielsen ${ }^{5}$, A.-L. Sand-Svartrud ${ }^{1}$, B. Slungaard ${ }^{6}$, S. Wigers ${ }^{7}$, I. Kjeken ${ }^{1} .{ }^{1}$ National advisory unit on rehabilitation in rheumatology, Diakonhjemmet Hospital, Oslo; ${ }^{2}$ Hospital for Rheumatic Diseases, Lillehammer; ${ }^{3}$ Betanien Hospital, Skien; ${ }^{4}$ Sørlandet Hospital, Arendal; ${ }^{5}$ The Norwegian Rheumatism Association, Oslo; ${ }^{6}$ Martina Hansen's Hospital, Bærum; ${ }^{7}$ Jeløy Kurbad Rehabilitation Center, Moss, Norway

Background: Multidisciplinary rehabilitation is widely used alongside medical treatment of patients with rheumatic diseases. Although beneficial effects of such rehabilitation have been demonstrated, patients are mostly back to their initial health status 6 to 12 months after discharge.

Objectives: To evaluate an add-on rehabilitation programme designed to enhance and prolong the effect of rehabilitation in adult patients with rheumatic diseases. Methods: We conducted a pragmatic multi-centre stepped-wedge cluster randomized controlled trial in six rehabilitation centres in Norway. All centres started simultaneously to include patients in the control phase (traditional rehabilitation), 